\title{
Breastfeeding across cultures: A social-constructionist view of differences in infant feeding norms between the United Kingdom and Kingdom of Saudi Arabia, 2011.
}

Dr : Hanaa Abualsoud ${ }^{1}$

\begin{abstract}
:
Breastfeeding is established as an important influence upon infant and maternal health. Also, it has positive effects for both the economy and the environment. Major influential organizations all agree that mothers should exclusively breastfeed their infant up to six months of age as breast milk is optimal to meet the infant's nutritional needs. These organizations include, The World Health Organization (WHO), The United Nations Children's Fund (UNICEF), The American Academy of Pediatrics (AAP), The UK Department of Health (UK DoH) and Health Ministries in the Middle East. The result of this study is concluded that there are several variables that can create the gap between the UK and KSA. Breastfeeding in the KSA is seen to be the norm whereas formula feeding an infant in the UK has taken to be the norm. This social construct has a vast impact on rates but also the knowledge and attitudes of Saudi mothers were more positive than British mothers. Both countries have historical religious influences and so religion was also an addition to these factors. Human lactation rates across the World are a complex issue influenced by many factors that are demographic, biological, social psychological and religions.
\end{abstract}

\footnotetext{
${ }^{1}$ Lecturer at Imam Abdulrahman bin Faisal University (in the KSA) - College of education in Jubail-kindergarten department.
} 


\section{Introduction}

During pregnancy, birth and infancy, babies holistically rely on their mother for healthy growth and development. Breastfeeding is one of the most essential contributors to the health of the new born baby(Blyth, reedy\& Dennis, 2002). During the last 20 years the benefits of breastfeeding have been researched on a mass international scale and more recently in the last decade. Adding to this, there has been a rise in advertisement and various campaigns have been erected to encourage, support and guide new mothers to this feeding technique (Manhire, Hagan \&Floyed 2007; Saadeh\&Akre 1996).

Many organizations promote breastfeeding as the optimal form of infant and mother health. Both the World Health Organization (WHO) and the United Nations Children's Fund (UNICEF) jointly launched the Baby-Friendly Hospital Initiative (BFHI) in 1991 (WHO 1991). In addition to these organizations, The American Academy of Pediatrics (AAP), UK Department of Health (UK DoH)and the Ministries of Health in the Middle East and Saudi Arabia have also encouraged and supported breastfeeding.

Exclusive breastfeeding for the first six months postpartum is recommended which translates to the concept of the infant only receiving breast milk and no other solids or liquids (apart from medications or water) (Kramer and Kakuma, 2002). The World Health Organization then recommends continued breastfeeding alongside solid foods for up to two years and beyond (WHO, 2003).

However, breastfeeding rates differ across the world. Not every mother initiates or continues breastfeeding and breastfeeding duration in Western cultures is particularly low in comparison to areas such as the Middle East (WHO, 2003). 
Numerous factors contribute to this including demographic, biological, social, religious and psychological variables (Thulier\& Mercer, 2009).

The aim of this study is to explore why breastfeeding rates differ across the world with a particular emphasis on comparing rates between the UK and the Kingdom of Saudi Arabia. It will examine differences in rates of breastfeeding initiation and duration before exploring the complex socio-cultural factors behind these decisions. Considering influences such as cultural differences, knowledge, support, attitudes of others and religious values it will examine why these differences occur and what lessons can be learned for Western culture.

To answer this question key themes will include, variations in breastfeeding initiation and duration across the world and an in depth exploration of the sociocultural factors explaining this. To examine Western influences data primarily from the UK will be used with additions from the US literature as culture is similar. For Middle Eastern cultures, data will primarily be used from the Kingdom of Saudi Arabia but also Kuwait again due to similar cultural factors. This work will explore the impact of these factors upon breastfeeding rates and ultimately a socialconstructionist view of differences in infant feeding norms between the UK and the KSA.

\section{Problem statement}

This study is to discover why there are differences in breastfeeding rates in the UK and KSA. According to world health organization which states that $76 \%$ of mothers in the UK initiated breastfeeding at birth compared to $91.6 \%$ of mothers in the Kingdom of Saudi Arabia in 2005. This study will be critically analyzed in relation to breastfeeding duration and compared and contrasted for the two cultures. Six main comparisons will be made between the two cultures: Mothers attitudes towards breastfeeding, attitudes of others towards breastfeeding, attitudes towards 
breastfeeding in public, maternal knowledge and confidence, support systems for breastfeeding, religious views

\section{Aims and Objectives of the Research}

The aim of the current research is to examine differences in breastfeeding rates between Western and Middle Eastern cultures and consider the socio-cultural influences behind these. Specifically, aspects such as knowledge, attitudes of society and access to factual information, familial support and professional assistance as breastfeeding will be considered with a focus on the UK and KSA. Overall, how is breastfeeding perceived in each region? Breastfeeding is the biological norm but is it seen as the normal, encouraged and supported behavior in each country!

\section{Questions of the Research}

This work will be broken down into 4 main sections:

1. What is breastfeeding and why does the subject matter?

2. Policy and breastfeeding.

3. Breastfeeding across the World.

4. Comparative study on breastfeeding in the United Kingdom and Kingdom of Saudi Arabia;

- How do social and cultural differences between the UK and KSA affect breastfeeding rates? Is breastfeeding socially constructed?

\section{The importance of this study:}

1- The current study is a step to enlighten educators and researchers to raise awareness of the importance of breastfeeding and mothers should breastfeed their children up to six months to avoid diseases, whatever social conditions. 
2- This study will help researchers in the future to pay attention to studies on breast-feeding and the danger of artificial-feeding on mother and child.

\section{Research Methodology}

The research methodology was based on a structured review of the literature, considering both qualitative and quantitative research. Sources of information included Holy books (Quran and Bible), peer reviewed journal articles, professional publications aimed at health professionals and those working with new mothers and government policy reports. The criteria for inclusion were English and Arabic language.

Search engines used include: Google, Google Scholar, Entrezpubmed, Science Direct, PubMed, some Government websites. Specific journals in the field were examined including Breastfeeding Medicine, International Journal of Breastfeeding, Journal of Human Lactation, Clinical Breastfeeding, Maternal and Child Health, Maternal and Child Nutrition, Midwifery and Women and Health. Publications used in identifying breastfeeding rates across countries were limited to the past 10 years, from 2000 to 2010 . 


\section{Sections 1}

\section{What is Breastfeeding and why does the subject matter?}

"You have the best chance to provide your baby with the best possible start in life, through the special bond of breastfeeding. The wonderful advantages to you and your baby will last a lifetime." Wiessinger (1996)

Breastfeeding can be defined as the process through which a mother feeds her infant at her breast. The term may also refer to breast milk fed to an infant from a bottle commonly known as expressed breast milk. Breastfeeding is nature's way of intending to feed an infant and is seen as the logical biological next step after birth (Morhbacher \& Stock, 2003). Numerous studies have shown the superiority of breast milk over formula milk with benefits for infant and maternal health, society and the environment (AAP, 2005). However, research has shown that many women do not breastfeed at all or struggle to do so (Bolling et al, 2007). Why is this and does it matter?

\section{Sections 2}

\section{Policy and breastfeeding}

Across the World Breastfeeding is recognized in official health policy as being the best method to feed an infant (AlFadli, Al-Jasem and Masoud, 2004). The World Health Organization, United Nations Children's Fund, American Academy of Pediatrics, UK department of Health and

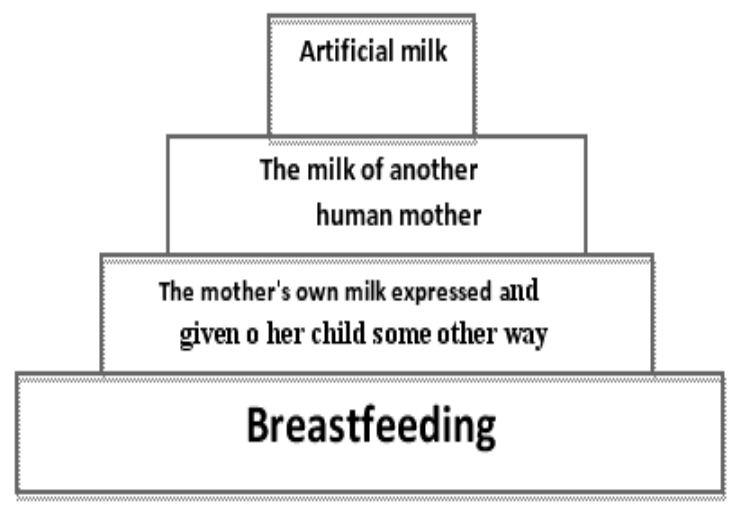
Ministries of Health in the Middle Eastall encourage breast milk as the optimal form of infant nutrition. The following hierarchy, which was produced by the WHO shows that formula milk comes at the fourth place after all the possibilities of feeding infants human milk. If breastfeeding fails then another mother's milk should be considered before opting for artificial milk.

\section{Sections 3}

\section{Breastfeeding across the World}

Despite clear similarities in breastfeeding policy across the world, breastfeeding rates differ largely between countries. The table below summarizes rates in developing and developed countries, published by the WHO Global Data Bank on Infant and Young Child Feeding (IYCF) and 'UK infants' survey 2010. The percentages of Kuwait, Iran and Malaysia were not up dated by WHO website so, it 
has been taken from last their studies which were published by international feeding journals. More details in table (1).

Table 1: Rates of breastfeeding across the World

\begin{tabular}{|c|c|c|c|c|}
\hline \multicolumn{2}{|c|}{ Country } & $\begin{array}{c}\text { Ever Breastfed } \\
(\%)\end{array}$ & $\begin{array}{c}\text { Exclusive breastfed } \\
\text { up to 6 months }\end{array}$ & $\begin{array}{c}\text { last date of } \\
\text { survey }\end{array}$ \\
\hline 1 & $*$ The UK & $81 \%$ & $1 \%$ & 2010 \\
\hline 2 & Sweden & $97.3 \%$ & $12.3 \%$ & 2007 \\
\hline 3 & The USA & 73.9 & 13.6 & $2007-08$ \\
\hline 4 & Canada & 90.3 & 14.4 & $2006-07$ \\
\hline 5 & Japan & $\mathrm{n} / \mathrm{a}$ & 21.0 & $2001-02$ \\
\hline 6 & Malaysia & 94.7 & 32.4 & 2006 \\
\hline 7 & $*$ The KSA & 91.6 & $\mathrm{n} / \mathrm{a}$ & $2004-05$ \\
\hline 8 & Kuwait & 92.5 & 10.5 & 2010 \\
\hline 9 & Bahrain & 95.1 & $\mathrm{n} / \mathrm{a}$ & 2002 \\
\hline 10 & Syria & $\mathrm{n} / \mathrm{a}$ & 28.7 & 2006 \\
\hline 11 & Iran & 90 & 28 & 2006 \\
\hline 12 & Iraq & $\mathrm{n} / \mathrm{a}$ & 25.1 & 2003 \\
\hline 13 & Bangladesh & 97.8 & 42.9 & 2007 \\
\hline 14 & Brazil & 96.4 & 39.8 & $2006-07$ \\
\hline
\end{tabular}

\section{Sections 4}

\section{Breastfeeding in the United kingdom\& the Kingdom of Saudi Arabia}

Table four previously illustrated that rates of breastfeeding differ across the World.

One stark contrast is the difference between Western and Middle Eastern countries, particularly in relation to the KSA and the UK. Table (2) explicitly compares rates of breastfeeding in Western and Middle Eastern countries: 
Table 2: Comparison between breastfeeding in KSA and UK

\begin{tabular}{|c|c|c|c|c|}
\hline \multicolumn{2}{|c|}{ Country } & Ever Breastfed & Exclusive Breastfed & date of survey \\
\hline \multirow{4}{*}{ 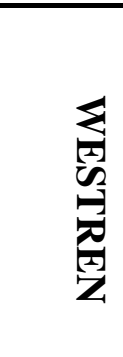 } & \multirow{3}{*}{ *The UK } & 69 & $\mathrm{n} / \mathrm{d}$ & 2000 \\
\hline & & 76 & 25 & 2005 \\
\hline & & 81 & $1 \%$ & 2010 \\
\hline & USA & 73.9 & 13.6 & 2007-08 \\
\hline \multirow{4}{*}{ 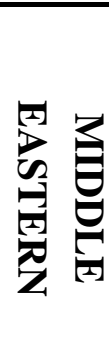 } & \multirow{3}{*}{ *The KSA } & 98.9 & $\mathrm{n} / \mathrm{d}$ & 2000 \\
\hline & & 92 & $\mathrm{n} / \mathrm{d}$ & 2003 \\
\hline & & 91.6 & $\mathrm{n} / \mathrm{d}$ & 2005 \\
\hline & Kuwait & 92.5 & 10.5 & 2010 \\
\hline
\end{tabular}

The next section will consider breastfeeding rates in these two societies and explore what socio-cultural factors might affect this. Why are women in KSA more likely to initiate breastfeeding than women in the UK and what lessons can the UK learn? Before this comparison begins it is necessary to consider biological implications that would stop a woman from breastfeeding. These factors are the same around the world. Around 2\% of women are physically unable to breastfeed (Powers, 1999; Huggins, 2000). Furthermore, breastfeeding is unsafe if the mother is taking particular medications (Hoover, 2002).Physical health difficulties, especially those surrounding the birth can also impact upon a woman's ability to breastfeed. Women are more likely to breastfeed when they have had a straightforward birth and can feed their baby as soon as possible after birth (DiGirolamo, GrummerStrawn \& Fein, 2008). Birth experiences can affect breastfeeding. High levels of 
analgesia, types of medication used and caesarean section are all associated with a shorter duration of breastfeeding due to delayed milk production, interactions with medications and maternal exhaustion (Baxter \&Cooklin, 2009).

However, research has shown that in most cases, women are physically able to breastfeed and should be encouraged to do so. Biological difficulties are not leading to formula use; instead complex social, cultural, attitudinal and psychological factors are influencing women (Neifert, 2001). It is these factors that will be critically analyzed in relation to breastfeeding duration and compared and contrasted for the two cultures. Six main comparisons will be made between the two cultures:

1. Mothers attitudes towards breastfeeding

2. Attitudes of others towards breastfeeding

3. Attitudes towards breastfeeding in public

4. Maternal knowledge and confidence

5. Support systems for breastfeeding

6. Religious views

\section{Breastfeeding in United Kingdom}

The UK is a western economically developed European country. The British Isles are situated in the north western coast of the Europe continent. The UK population, according to the office of national statistics census, 2001, is around $62,453,759$. $72 \%$ of which are Christians, $2.8 \%$ Muslims, $1.0 \%$ Hindu, $0.6 \%$ Sikh, $0.5 \%$ Jewish, $0.3 \%$ Buddhist and other religions. English is the UK's official language (Census; Office for National Statistics, 2001).

The UK Department of Health advocates exclusive breastfeeding for the first six months postpartum followed by continued breastfeeding up until the first year and beyond (DoH, 2007). However, breastfeeding rates in the UK are still below the 
level recommended by WHO, which is exclusive breastfeeding for the first 6 months of the child's life(Brown, Raynor, \& Lee, 2011).

Breastfeeding rates in the UK are increasing overtime, particularly between 2005 and 2010. Studies and surveys carried out by the NHS Information Center and IFF Research provide data to indicate an increase of breastfeeding rates in the UK from $62 \%$ in 1990 to $76 \%$ in 2005 and further to $81 \%$ in 2010 . "Initial breastfeeding rates in 2010 were $83 \%$ in England, 74\% in Scotland, 71\% in Wales and 64\% in Northern Ireland" (The NHS information Center \& IFF research, 2011)

\subsection{Breastfeeding and mother's socio-economic classification.}

Breastfeeding rates vary from one region to another. However, there is a remarkable difference in attitudes towards it among women of different backgrounds. Women with a higher educational level and professional and managerial jobs are most likely to initiate breastfeeding. "Across the UK, $90 \%$ of women in managerial and professional jobs began breastfeeding (up from $88 \%$ in 2005), compared with $74 \%$ of those in routine and manual occupations and $71 \%$ of those who have never worked (both up from 65\% in 2005)" (Boseley, 2011).Breastfeeding rates are lower among low-income women in the UK (Entwistle, Kendall \& Mead, 2007).

Figure 1: Breastfeeding rates in UK between 1995 and 2010

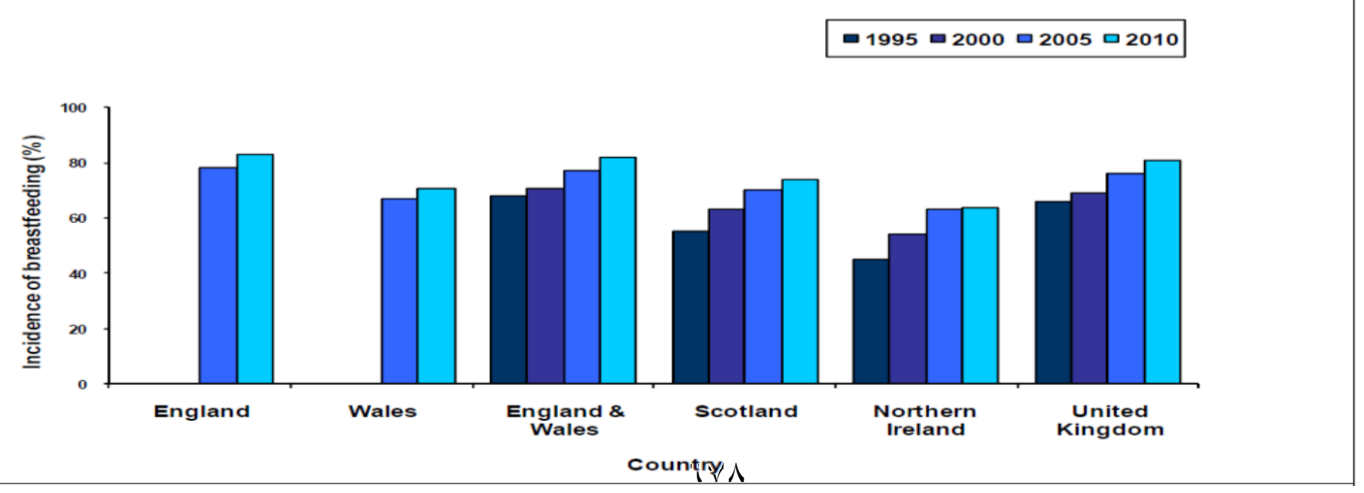




\subsection{Breastfeeding and full-time education.}

Boseley highlighted a relationship between women's level of education and breastfeeding initiation. $91 \%$ of women who left full time education at the age of 18 have initiated breastfeeding, while the percentage was only $63 \%$ of who left full time education at the age of 16 or younger (Boseley, 2011).Figure three below shows that the percentages of mothers initiate breastfeeding increase proportionally with education.

Figure 2: Incidence of breastfeeding by mother's socio-economic classification (NS-SEC) and country (2010)

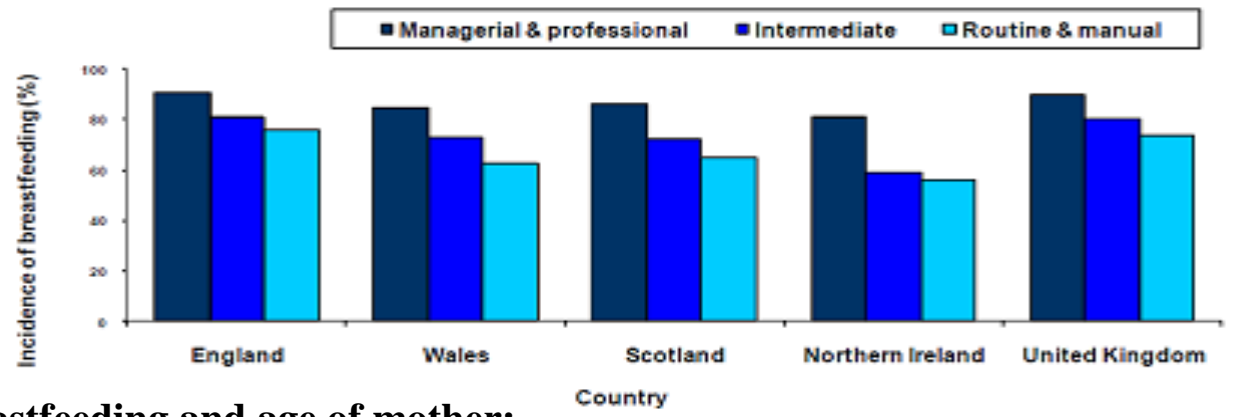

1.3 Breastfeeding and age of mother:

The NHS information Centre \& IFF Research confirms a strong relationship between breastfeeding and the age of the mother. They carried out a national survey in 2010, which showed that older mothers are more likely to breastfeed. The study reported that across the UK, the highest percentage of breastfeeding (87\%) was among mothers aged 30 and over, while the lowest was $20 \%$ among mothers aged 20 and under. Further research confirms that younger mothers are less likely to initiate or continue breastfeeding (Brown, Raynor, \& Lee, 2009). 
Figure 3: incidence of breastfeeding by age completed full time education and country (2010)

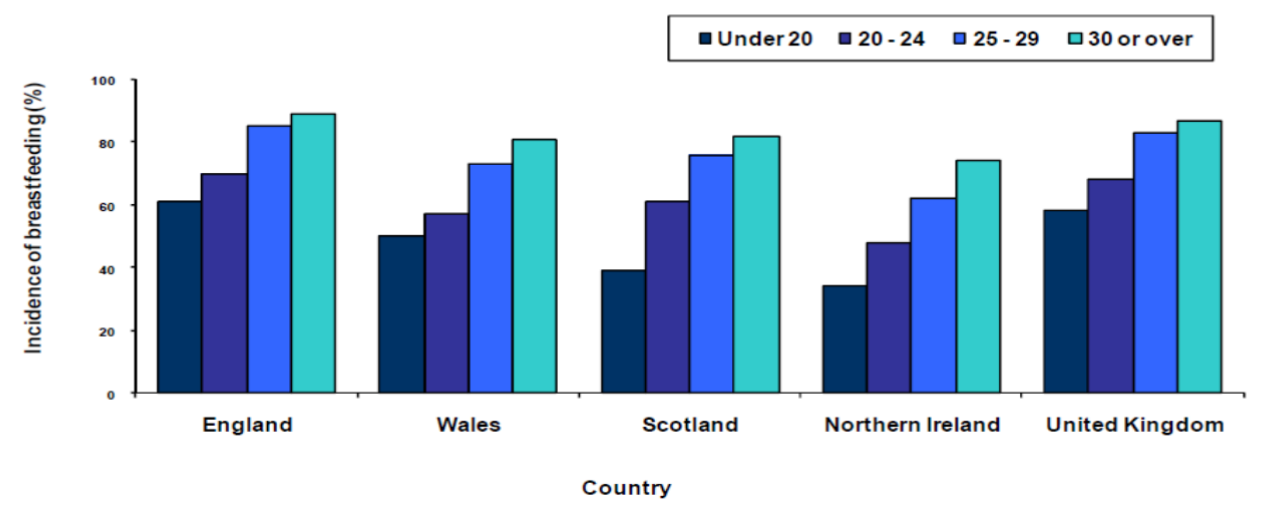

\subsection{What factors influence decision to breastfeed in the UK?}

Breastfeeding although the biological norm, is affected by many complex social and cultural factors. Despite a clear 'Breast is best' message in the UK driven by the Department of Health and Health Professionals, nearly $20 \%$ of women in the UK never breastfeed with less than half doing so by six weeks postpartum. What factors affect this decision?

Figure 4: Incedence of breastfeeding by age and country (2010).

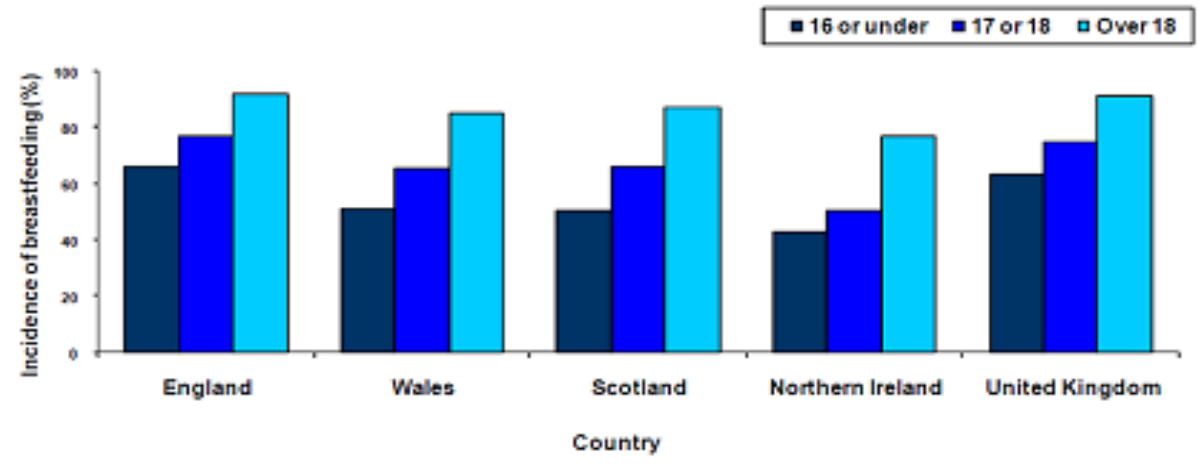




\section{Maternal attitudes towards breastfeeding}

Negative attitudes towards breastfeeding are associated with formula use. These include believing that breastfeeding is inconvenient and ties you to the baby (Earle, 2000). Mothers want to be able to share feeds with others, to be able to leave the baby and to 'get their lives back' (Murphy, 1999). Family and friends may encourage the mother to use formula as it means the mother can have a break from the infant and that others can participate in caring for the infant (Earle, 2002; Zimmerman \&Guttman, 2001).

Others believe that formula milk will make the baby more settled and sleep longer. Formula is more difficult to digest than breastfed milk and therefore babies often go longer between feeds. Although this is believed to have a negative effect upon the infant's digestive health, mothers may perceive it as convenient. If exhausted and sleep deprived with a baby who will not settle they may choose to use formula milk (Thulier\& Mercer, 2009).

Other commitments can mean that a mother chooses not to breastfeed. Returning to work is a key problem. Although mothers can express breast milk they may find this difficult to do and choose to use formula (Hoddinott, Tappin, \& Wright 2008; Ogbuanu et al. 2011a). In countries where there are less pressure for women to return to work, breastfeeding rates are higher (Ogbuanu et al. 2011b).

Further commitments might include feeling that she has a number of other children to look after or elderly relatives to care for. Mothers can feel pressurized to introduce formula so that the baby feeds less often and sleeps better at night so that they can give their time to other children and needs (Thulier\& Mercer, 2008).

\section{Attitudes of other people}

Negative attitudes of other people can prevent a woman from breastfeeding. Where support for breastfeeding from a partner is strong, mothers are more likely to 
breastfeed (Thulier\& Mercer, 2009). However, negative pressure from a partner to stop breastfeeding is associated with formula use. Partners may not want the mother to breastfeed or want to participate in the feeding themselves (Earle, 2000). Similarly, negative comments from family and friends are linked to formula use. Mothers who are ridiculed or pressurized into using formula are more likely to do so (Ingram et al, 2002).

Familial and peer support is also associated with an increased duration of breastfeeding (Gill, Reifsnider\&Lucke, 2007; Ingram et al. 2002) whereas ridicule or encouragement to use formula is associated with a decreased duration (McFadden \& Toole, 2006). In particular support from the woman's partner is essential (Sullivan, Leathers \& Kelley, 2004). Inconsistent or conflicting advice, on the other hand, or lack of information from health professionals is associated with poorer initiation and continuation rates (Berridge, McFadden, Abaymoi\& Topping, 2005).

\section{Attitudes towards feeding in Public}

Some women feel embarrassed about breastfeeding in front of other people, and often exacerbated by negative comments received when doing so (Dykes et al, 2003). Also, many mothers feel embarrassed about breastfeeding in public when they are out and about and feel that formula feeding would help them avoid this. Linked to attitudes towards breastfeeding is how a woman feels about her body and breastfeeding, particularly in front of other people. This is especially true for younger mothers (McFadden \& Toole, 2006). Mothers are embarrassed by factors such as leaking nipples, changes in the appearance of the breast and feeling that the infant still owns her body (Aroraet al, 2000). 
In the UK the new Equality Act 2010 states "that it is sex discrimination to treat a woman unfavorably because she is breastfeeding. It applies to anyone providing services, benefits, facilities and premises to the public, public bodies, further and higher education bodies and association. Service providers include most organizations that deal directly with the public. Service providers must not discriminate, harass or victimize a woman because she is breastfeeding. Discrimination includes refusing to provide a service, providing a lower standard of service or providing a service on different terms. Therefore, a cafe owner cannot ask you to stop breastfeeding or refuse to serve you" (Maternity action, 2011). According to a survey conducted by the UK Department of health, $84 \%$ of people do not object to breastfeeding in public if it is done discretely. "However, $67 \%$ of mothers were worried about general opinion being against public breastfeeding" (DoH, 2004).

Squire argues that some people have objections to breastfeeding in public view in the UK. The sexual nature of breasts ultimately links breastfeeding with female sexuality. This can be an influential factor that genuinely affects omens breastfeeding success. Squire also highlighted the influence of the media on public opinion towards breastfeeding. The majority of media aspects, such as television programmes, newspapers and magazines characterize the female breast as sexual. "In the UK there is a strong cultural preference for sexualized breasts. When women breastfeed they may be seen as transgressing the boundary between motherhood and sexuality" (Squire, 2009).

\section{Knowledge and confidence}

Breastfeeding can be a difficult skill for women to master. Problems such as getting the infant to latch on correctly, pain from sore or cracked nipples or infections such as mastitis and thrush can all lead to formula use (Scott, Binns, Oddy\& Graham, 
2006; Wambach, Campbell, Hill, Dodgson, Abiona\&Heinig, 2005). Women in the UK often do not know how to overcome these problems or think they are a reason to stop breastfeeding (Thulier\& Mercer, 2009). Mothers can find these difficulties very distressing, both emotionally and physically (Amir \& Ingram, 2008).

How confident a woman feels breastfeeding her baby is also linked to duration (Chezem et al. 2003). Mothers often worry that they cannot view how much milk their baby is drinking or worry that the baby feeds too frequently ( $\mathrm{Li}, \mathrm{Fein}, \mathrm{Chen}$ \&Grummer-Strawn, 2008). This can be perceived as having a lack of milk (Wambach\& Cohen, 2009). As breastfed infants often put on weight more slowly than formula fed infants, mothers may worry that their infant is not receiving enough nutrients and turn to formula milk (Lewallen et al. 2006; Sachs, Dykes \& Carter, 2006). Anxiety about breastfeeding is linked to a shorter duration (Miracle et al, 2004). These misconceptions are often passed down by older generations and peers. In particular, grandmothers can pass on out of date knowledge with women feeling pressure to follow what their elders and peers suggest (Sachs, Dykes \& Carter, 2006).

\section{Support systems for breastfeeding}

A number of studies have shown that mothers are affected by not having enough professional support to breastfeed. Mothers are more likely to initiate and continue breastfeeding when professional guidance, advice and support is strong. However, many mothers find that health professionals are too busy to give support or give contradictory or inconsistent advice, often offering formula milk as a solution (Brown \& Lee, 2011).Women are often motivated to breastfed, but a lack of professional support and advice affects this. Mothers need more help showing 
them how to breastfeed, with guidance postnatally and long term information about continuing breastfeeding (Cleveland \&McCrone 2005).

\section{Religious Views}

Finally, breastfeeding will be considered from a religious perspective. According to the 2001 UK census, Christianity is the main religion in the UK. There were 41 million Christians in 2001 (about 72\% of the population). This percentage includes "the Church of England, Church of Scotland, Church in Wales, Catholic, Protestant and all other Christian denominations" (Census; Office for National Statistics, 2001).

The Holy book of the Christians is known as the Bible. This comes in two parts that is the Old Testament and the New Testament. On the basis of this research both versions will be used to gain a fuller picture of the rules around breast feeding from a Christian perspective.

The Bible does not refer to breast feeding specifically and does not go in detailed depth of how and why women should or should not breastfeed. This is because the Bible argues; a child does not just want breast milk to thrive but needs; love, comfort, safety, a stable environment and emotional and spiritual affection. As a child grows older being brought up through a loving and nurturing home he (the child) becomes closer to god and gives a positive contribution to society and plays a religious and righteous role (St, Beeman, 1983:19).

In saying that, there are areas within the Bible that argue the importance of breast feeding. Not just the actual milk itself but the affectionate bond between the mother and child within this process. A verse in the Holy Bible stresses this point, 'Yes, you are the one who brought me out from the womb and made me feel secure on my mother's breast'(Pslams 22:9). From this quote it is evident that the Christian 
belief is based upon affection and attachment of the mother and child. Here this quote refers to a child who is just born and is given to the mother straight away to seek comfort and security. It can be seen that this trend has carried on until today, where after birth the mother longs to hear the screams of her child and after being cleaned is given straight to the mother to breastfeed. This milk today is known as the golden milk. That is a strong source of nutrients and antibodies to provide for the delicate child (St Beeman, 1983:38).

The value of breastfeeding is at a great importance to the Christian religion. In the Bible there is an example, that argues if a person does not become Christian or listen to the Christian religion they are like a "child who is weaned from milk, or those just taken from their mothers breast" this identifies the value of breastfeeding and gives a sample to the meaning of the deprivation of natural milk sources is to the Christian belief (Isaiah, 28:9). The Pope argues that the word nipple is an embarrassing word to most people in society or within the church. However, he continues this should not be the case and that is the nipple that brings wisdom and knowledge to the person (Pope Shenouda III, 2010). The Pope takes this from what Luke 11:27 sates that a woman in a crowd of people once shouted "happy is the body which gave you birth and the breasts from which you took milk." Another religious perspective taken from the Bible is the prophet Jab who said to his son "both the womb and breast are important to create life". Isaiah agrees with this and states, "For you will nurse from hersatisfying breasts and be nourished, you will feed with joy from her milk- filled breasts" (Isaiah, 66:11). Job within the Bible questions his mother, "why did I not die at birth, and why did I not expire" (Job, $3: 11)$. It can be suggested that this is an evidence based source that as he was breastfeed and the breast milk kept him alive. 
The Bible feels so strongly about breastfeeding that it is linked to an example if a person is to be bad they are like "the fatherless child is snatched from the breast, the infant of the poor is taken as a pledge" (Job, 24:9).

As a last example, there is a phrase in the Bible that again states the importance of breastfeeding from a religious perspective "Can a woman forget her baby who nurses at her breast" God questions and it continues in the Bible "can she hold compassion from the child she has borne? Even if mothers were to forget I could never forget you" (Isiah, 49:15).

\section{Does this influence woman in the UK?}

It can be seen that there are earlier Biblical texts advocating breastfeeding. According to Muers(2010) "several recent works on the subject acknowledge the religious terms and symbols that have helped form breast-feeding as a social and cultural practice". Although there have been a few attempts in the Christian texts that try to explain the importance of breastfeeding, Muers(2010) explains "the problem was that I could find very little material about breast-feeding that said much about children. The picture we receive very often is that breast-feeding is something women do, or don't do, or choose to do, or try to do-for, or to, children". Overall, religion in the UK has a low impact upon maternal decision to breastfeed.

In summary, although physically many mothers in the UK are able to breastfeed, many social, attitudinal and psychological reasons prevent them from doing so. Formula milk is very common in the UK with some arguing that the UK has become a 'Formula feeding culture' (Scott et al, 2003). Few women breastfeed for a long duration or exclusively meaning it is common to see women feeding with bottles. Images of bottles are everywhere and associated with having a baby. Knowledge about how to formula feed is strong and knowledge about breastfeeding 
weak. Therefore breastfeeding is something 'strange' with family and peers unable to help with difficulties or even understand why the mother is choosing to breastfeed. Formula is seen as the more convenient, easier option which leads to babies sleeping for longer and being more settled. It is the cultural, accepted norm in UK society to formula feed, leading to low levels of confidence, knowledge and success with breastfeeding.

\section{Breastfeeding in Kingdom of Saudi Arabia}

Saudi Arabia is located in the Middle East. It is bordered to the Eastern Persian Gulf to the north of Iraq and Kuwait and to the west of the Red Sea. The population of Saudi Arabia has reached around 27 million. Arabic is the official language, while English is spoken in business circles. Islam is the main religion and there are no other religions in this country.

Saudi's economy is based heavily on oil and natural resources. The government runs the majority of the economic activities. "It possesses more than $20 \%$ of the world's proven petroleum reserves, ranks as the largest exporter of petroleum, and plays a leading role in OPEC. The petroleum sector accounts for roughly $80 \%$ of budget revenues, 45\% of GDP, and 90\% of export earnings" (Trading Economics, 2011).

"Saudi Arabia has witnessed a massive important in socio-economic development in the past 30 years, with profound progress in health, education, housing and the environment". "Child health care indicators show a marked decline in child mortality, mainly owing to the reduction in incidence of communicable diseases as a result of high immunization coverage, improved nutrition, adequate safe water 
and sanitation, and reduction of acute respiratory illnesses" (WHO, Saudi Arabia, 2006-2011:23-24).

According to WHO, health development in Saudi Arabia is facing some serious challenges. The most important aspect of these challenges is financing health care services. These services have been funded by the public sector; however, it is becoming very difficult to ensure the continuity of those funds. Another challenge is strengthening the organization of the health services in order to meet growing needs(WHO, Saudi Arabia, 2006-2011:7).

Breastfeeding in the Middle East is an old established concept. It is mentioned in detail in the Quran, Muslims Holy book, as well as in the teachings of Prophet Muhammad. The Holy Quran states that the period of breastfeeding should be two years in order to provide infants with the fundamental healthy nutrients. Breastfeeding in religion is explored in the last section of this part.

Breastfeeding in the Middle East is not explored in depth and there are fewer studies and research about it comparing to the west (Europe and America). Perhaps the reason for that is the Quran laid down breastfeeding; therefore it is an undebatable concept. However, breastfeeding studies are becoming increasingly important in the KSA and the Middle East.

\subsection{Incidence of breastfeeding.}

Breastfeeding initiation and duration have been declining since the last decade. In the year 2000 the percentage of ever breastfed children was 98\%, with mean breastfeeding duration of 6.5 months. This percentage shows that the majority of mothers had initiated breastfeeding; although, $72 \%$ of them "had introduced bottlefeeding by the end of the first month" (Al-Jassir, et al, 2004 ). However, levels of breastfeeding initiation are still high at 91\%, higher than many countries in Western society. 
El Mouzan et al. carried out a study between 2004 and 2005 on a sample size of 5339 children. The study showed that 4889 children were breastfed at birth (91.6\%). Bottle-feeding at the age of 1 month was introduced to $51.4 \%$ of the children. $90 \%$ of the children were bottle-fed by the age of six months(WHO, 2004-05 \& El Mouzanet al 2009). The most reasons of starting bottle-feeding early was due to mothers reporting a lack of milk production to satisfy their babies, mothers study or return to work (Al-Jassir, et al, 2004, El Mouzanet al 2009)."Optimally, solids would not be offered to infants before 6 months of age and bottle-feeding would be unnecessary"(Al-Jassir et al 2006). These results show that exclusive breastfeeding in KSA between 2000 and 2005 was far from the WHO recommendations which is up to six months after the child's birth(Al-Jassiret al 2004, El Mouzanet al 2009).However, figures are higher than in the UK (Bolling et al, 2007).

A study was carried out recently in Al Hassa, an eastern city in KSA, and was published in April 2011. The study reported that $77.8 \%$ of the children were ever breastfed. $32.9 \%$ of the children started mixed feeding by the age of 2 months, and only $12 \%$ of them were exclusively breastfed up to the age of 6 months. Therefore, "the rate of initiation and exclusively of breast-feeding in Al Hassa is far below the WHO recommendations" (Amin, Hablas\& Al Abd Al-Qader, 2011). The sample size for the study was 600 children and it was carried out in one city only. Therefore it does not reflect breastfeeding levels across the kingdom.

\subsection{Breastfeeding and mother's level of education and socio-economic classification.}


A study conducted by Khoja and Farid in 2000 to determine the rate of bottle-fed children before the age of 12 months. The percentage was $66 \%$. The rate was higher among the children of working mothers, $(77 \%)$ in comparison to children of non-working mothers $(63 \%)$. The study also reported that bottle-feeding was more common in urban areas compared to rural ones. The rate was proportional to the mother's level of education. Breastfeeding rate was significantly higher among less educated mothers in comparison with the more educated ones. Other studies conducted by Al-Shehri et al in 1995, Al-Jassiret al in 2004 have shown that the duration of breastfeeding inversely proportioned with the mother's level of education. Illiterate mothers breastfed for longer, and that period declined gradually with the increase of the mother's level of education. Studies in Kuwait have similar relationship (Al-Bustan, 1987). The main reason for that was: women returning to their jobs after a certain period of maternity leave.

\subsection{Breastfeeding and age of mother}

Lower duration of breastfeeding was found in young women when compared with older women whose duration was more than a year (Al-Shehri et al, 1995, Khalil et al 2003; Al-Jassir et al, 2004).

\subsection{What influences maternal decision to breastfeed in KSA?}

Levels of initiation of breastfeeding far exceed those in the UK with women tending to continue breastfeeding for longer. Why might this occur? How does socio-cultural context influence women in KSA? Below the same social, cultural, attitudinal and psychological variables affecting breastfeeding in the UK are considered for Saudi Arabia. Do these vary between the two cultures? 


\section{Mothers' attitudes towards breastfeeding}

Attitudes towards breastfeeding in the Middle East are positive (Al-Bustan, 1987). There are high rates of positive attitudes. $98 \%$ of women agreed that mother's milk is the most nutritious baby food. $95 \%$ of women believed that breastfeeding is a mother's duty dictated by religion. $90 \%$ of participants had said that they would advise their female friends and family members to breastfeed their infants.

Al-Jassiret al (2006) have suggested another factor that leads mothers to opt for mixed feeding. Mothers might be absent during feeding time due to work or study commitments. "This may be because educated mothers were outside the home more often than illiterate mothers and thereby felt they needed to introduce bottles earlier" (Al-Jassir et al 2006). This coincides with the fact that breastfeeding rate is lower among working mothers in comparison with stay at home ones. It also shows the inversely proportional relationship between the level of education and breastfeeding initiative and duration in KSA.

A study in Kuwait has shown that Kuwaiti mothers had similar reasons for introducing formula milk. The main two reasons were: insufficiency of breast milk and the inconvenience of breastfeeding for working mothers (Al-Bustan, 1987).

\section{Attitudes of others towards breastfeeding}

The mother's decision to initiate breastfeeding is encouraged by the amount of support provided by her partner and family members. Two KSA studies have investigated whether breastfeeding initiation was influenced by paternal attitudes. The outcomes of the two studies were controversial; with one finding that mothers were more likely to initiate breastfeeding if their husbands supported them and encouraged exclusive breastfeeding, (Ogbeide et al, 2004), whereas, the second study has found no association between Saudi fathers' attitudes towards 
breastfeeding and breastfeeding initiation ( Al-Ayed \&Qureshi 1998,in, Dashti et al, 2010).

\section{Breastfeeding in public}

"In Saudi Arabia, it is not uncommon to see a totally veiled woman bearing her breast to feed her infant in public with no one taking notice, except, perhaps, a foreigner" (Riordan, 2005, p.718).

There is no legislation to prohibit women from breastfeeding in public in KSA and in the Middle East in general. Women can breastfeed in parks, restaurants and shopping malls. In fact, media always emphasizes the importance of breastfeeding and encourages women to undertake it, providing advice on how to breastfeed in public without facing difficulties or problems. Women can simply use a special cover up to help them not to expose their breasts while breastfeeding (Philips, 2004).

\section{Knowledge and confidence}

Breastfeeding in Gulf countries, KSA and Kuwait in particular, has not yet been studied and investigated thoroughly. Therefore, sufficient statistics, which can reflect mothers' knowledge and attitudes towards breastfeeding in these countries, are very limited (Al-Fadli, et al, 2004).

Al-Bustan (1987)found women received information and support about breastfeeding from a number of sources. He reported that the major source of knowledge, which participants had on breastfeeding benefits, was family, such as grandmothers and relatives and also friends. Media; including TV, newspapers and books, was another important source of knowledge. However, doctors and nurses input had scored only $10 \%$. 
A more recent study, conducted by Al-Jasser et al in KSA in 2006, has shown 5 major knowledge sources of breastfeeding benefits. The majority of participants had received health information from medical staff (44.9\%). 26.8\% had gained their knowledge from relatives, $17 \%$ from mass media, 9.3\% through school education and $1.2 \%$ from infant formula manufacturers and distributors.

Before that, another study in Kuwait, conducted by Al-Fadli et al, in 2004, had reported that almost three quarters of participants (73\%) had received information on breastfeeding from medical staff. Amongst the ones who had knowledge on breastfeeding benefits, $96.4 \%$ regarded it as the best for infants.

Al-Jassir et al. have explained, in their 2006 study, that in KSA, the source and level of mothers' knowledge on breastfeeding health benefits were significantly related to their age and level of education. The older the mother was, the less knowledge she had. $80 \%$ of mothers aged $20-40$ years old had received health education, particularly on breastfeeding benefits compared to those older than 40 years old (53\%). On the other hand, $84.2 \%$ of educated women to university level had received health information relevant to breastfeeding as opposed to illiterate mothers $(67.3 \%)$. Moreover, the majority of participants $(88.6 \%)$ thought that colostrum was good for infants. Only $1.2 \%$ of them thought it was harmful. This negative idea about colostrums was most popular amongst illiterate women, and was based on some false believes such as: colostrums is not milk, it is dirty and stale and might kill infants (Dashti 2010). This clearly reflects that positive attitudes towards breastfeeding are proportional to mothers' level of education. However, over $90 \%$ of mothers had initiated breastfeeding straight after birth in order to provide their infants with the nutrients included in colostrums, $(94.4 \%$ educated, and $88.3 \%$ illiterate). 
Amin et al (2010) have conducted the most recent study, which assessed knowledge towards breastfeeding in Al Hassa, eastern suburb of Saudi Arabia, in 2011. The study has revealed that Increased maternal age, multiparty (three or more children) and natural delivery were significantly good predictors of early breastfeeding initiation. In addition to that, less educated mothers with low income as well as mothers in rural areas were more likely to exclusively breastfeed their infants.

\section{Support systems}

The Baby friendly hospital initiative program is supported in KSA. The Saudi Ministry of Health has taken appropriate actions to implement the 'ten steps for successful breastfeeding' plan, which was laid down by WHO in cooperation with UNICEF.

Nowadays, Baby friendly hospitals in KSA run training courses to equip medical staff with the skills and knowledge required to help mothers breastfeed successfully. Also, these courses enable them to provide advice for mothers and help them to choose what is best for them as well as for their infants. Most mothers, in recent years, acquire their breastfeeding knowledge from medical professionals (doctors and nurses), whereas, in the past this knowledge used to be passed down to mothers from older generations.

Medical professionals encourage Saudi mothers to breastfeed through advocating breastfeeding benefits and highlighting the disadvantages of formula milk. A dedicated team of nurses has been trained especially to help mothers to overcome any difficulties, which might face them during their breastfeeding process. The team is also responsible for educating mothers on breastfeeding correctly (AL Jazairi, 2011).

The Saudi Ministry of Health has implemented the following procedures: 
1. Establishing special training programmes for nurses working in maternity wards.

2. Caring for pregnant mothers and raising awareness among them of the benefits of breastfeeding. They are invited to attend pregnancy clinics set up especially to advocate breastfeeding benefits and procedures. Pregnant mothers are strongly encouraged to attend specifically during the last months of their pregnancy.

3. Encouraging mothers to start breastfeeding during the first hour after birth, even if they don't have milk.

4. Feed infants with mother's milk only, unless otherwise for medical reasons.

5. Avoid introducing any other liquid to infants beside mother's milk.

6. Avoid introducing pacifiers to infants.

7. Restrict formula milk advertising in hospitals.

8. Allocate rooms for breastfeeding, within female wards in hospitals, to facilitate breastfeeding during times when mothers attend hospitals for medical reasons (Al Shamasy et al, 1999).

The custom in the Middle East, including KSA and Kuwait, is that mothers spend their postnatal period at their parents' (mothers in particular) places. This period can be up to 40 days especially after having the first and the second child. During this period, mothers care for and support their daughters. They pass down to their daughters their knowledge and experience of caring for newborns, how to breastfeed them and bath them. They also provide their daughters with dietary advice. Midwives do not visit mothers after leaving hospitals; therefore, grandmothers are usually the main source of knowledge and advice. However, hospitals equip mothers with a wealth of instructions and advice during their stay. 
The role of baby friendly initiative medical professionals in KSA is limited within hospitals. Home visits have not been initiated yet.

\section{Religious views}

Islam is the main religion in KSA, at $100 \%$ of the population. The Muslims Holy book is known as the Quran that was brought by their prophet Mohammed over a period of 23 years (BBC, 2009).

General research in regards to breastfeeding has not been highlighted or thought about greatly in medical or scientific terms. The importance of breastfeeding and its importance of it can be seen in the Quran prior to 14 centuries. It is breastfeeding and the weaning processes that have been spoken about in great length 14 times in 8 different verses specifically. The Quran assures women that 2 years is the maximum time that a mother should breastfeed her child. Thus, the nutritional value of breastfeeding is two years which found by Dewy's (2001) study is not a new discovery. It has been written in the Quran for Muslims since 1400 years that the two whole years of breastfeeding is the best; "Mothers shall suckle their children for two whole years; (that is) for those who wish to complete the sucking... if ye wish to give your children out to nurse, it is no sin for you. Provided that ye pay what is due from you in kindness"(Al-Baqara 233). This verse explains that, a mother can breastfeed her child for two full years or she has the opinion to wean her child before that time, she also has the choice to provide a wet nurse and the father must pay her a wage. However, this must be discussed by both the mother and father before making such a decision to wean the child. "It is mentioned in the Quran "if they both decide on weaning by mutual consent and true consultation, there is no blame on them." The Quran does not insist each mother must breastfeed her child but encourages the action of putting the infant on the mother's breast (AlShehri, et al 1995). 
Another verse within the Quran discusses the duration of the pregnancy and breastfeeding of the child. It said "and the bearing of him and the weaning of him is thirty month"(Al- ahqaf 15). In regards to this verse it discusses the child in the 9 months of being in the womb. This leaves with 21 months of breastfeeding for the child that the Quranic verses believe it is sufficient enough. The last verse argues "and we have enjoyed upon man concerning his parents. His mother beareth him in weakness upon weakness, and his weaning is in two years. Give thanks unto me and unto thy parents. Unto me is the journeying"(Luqman 14). Here the Quran recommends that a child needs to give thanks to their parents and especially to the mother after carrying the child during pregnancy, the feelings of tiredness and strain and the two years of breastfeeding later on. It can be argued that the Quran suggests high value for the mother and especially for a mother who breastfeeds or provides breast milk to her infant. It is from this that the Muslims take such versus and translates them into everyday living.

There are other influences on the Muslims other than the Quranic verses. These include Hadiths that are brought from their Prophet Mohammed (Al habal, 2008).A few examples include; "god gave a Childs livelihood in his mother's breast, one of the breasts include drink for the child and the other brings the food" (Amile, 15: 176).A companion of the prophet extends this thought and adds "there is no greater milk than the milk of a mothers breast that will fulfil a Childs developmental need"(Ali ibin abe talib, nahaij al bala3'a, 15: 121).

An Islamic caller (Mansoor Rifaae, 2006) argues, feeding the child after birth is very important as it extends brain development, hearing, eye strength and bone growth. The mother's breasts are a natural cleanser that holds no bacteria or germs. This continues on to say that a mother's milk as mentioned before is perfectly 
created to suit a child's needs. For example the thickness of the milk is dependent on the child's age and as the child grows older the milk becomes thicker to make more filling feeds and provides different sources or nutrients and anti-bodies with each developmental stage, the milk is also very dependent on the weather conditions, if for example, the weather is hot the child is more likely to have thinner more runny milk to satisfy the thirst and vice versa in more colder conditions. Islam does not allow a mother to become pregnant whilst breast feeding as it becomes dangerous for the mothers and the infants health. The mother needs time to recover and regain her strength and still be strong enough to provide for the other child Al Rifaae suggests that it is during or after the weaning processes that she can be pregnant again.

After researching different sources from the Islamic religion it can be seen that the religion clearly identifies a strong relation between the health of the child and the benefits of breast feeding. A study by Al Shamasy et al, (1999) found that over $1,000,000$ children die each year due to different illness such as dihoerra, acute infections and other illnesses. The correlation found that all these children were not breastfed during infancy and Al Shamasy et al continues to argue that these illnesses may have been potentially avoided if these children were breastfed.

There is a question that presents itself: at what age is it recommended that a child continues to be breastfed. Is it at the age that the Quran recommends that is two years?

The World Health Organization answers this though a study called guidance to how to treat server dihoreha. Within their programme in how to treat this dihoreha illness, there was the absolute dependence on a child's breast feeding for the period of $4-6$ months or any time after that the child may want to continue to breast feed. This may continue until the child researches the age of 2 years. This is one of the 
most important sources of protection to the child from dihoreha during this age. Therefore, the mother milk becomes the most adequate forms of feeding for young infants at this age, the reasons for this includes the different properties the breast milk carries such as antibodies to prevent infectious illnesses, including dihoreha. From studies such as this it can be seen that within the western civilization there are many supporters around the idea of breast feeding children for a continual time of two years if possible. Therefore we found the west has reached a conclusion after a long research process that the best implementation was already written in the Holy Quran 1,400 years ago (Dogramaky, 2005).

\section{Does this influence in the KSA?(Religion in culture)}

The culture of Saudi Arabia has taken much of its dynamics from religious aspects. The Holly Quran emphasizes the importance of breastfeeding and clearly states that the duration of breastfeeding should be for 2 years. It could be thought that the percentage of Muslim mothers who breastfeed are higher than other religions because of the verses in Quran stressed that point as seen in Al -Baqara 233 "Mothers shall suckle their children for two whole years; (that is) for those who wish to complete the sucking... if ye wish to give your children out to nurse, it is no sin for you. Provided that ye pay what is due from you in kindness". However, not all mothers in Saudi Arabia breastfeed their children because it is not compulsory within the Islamic religion. Some mothers decide to bring a wet nurse while others do not breastfeed at all.

However, (Al-Shehri, et al 1995) have explained that verse in 3 points: 
First: "the Quran did not say that each mother should feed her child, but insisted on suckling, which means the act of putting the infant on their mother's breast. Therefore, the advantages of suckling had been stressed in the Quran".

Secondly: "the breastfeeding period for those who wish to complete the term is two complete years".

Thirdly: "weaning is allowed before completing the term (2 years) on condition, that this decision takes place by mutual consent between the father and mother and after they both discuss the pros and cons of taking such decision".

Overall, religion in the KSA makes a positive perspective among Saudis mothers to breastfeed contrary to the UK which has a low impact upon maternal decision to breastfeed.

In summary, it was noted that the most popular feeding plan was a mixed of two. In other words, mixed feeding (breast milk and formula milk) is very common in KSA; nearly $72 \%$ of mothers had introduced formula milk by the end of the first month (Al-Jassir, et al, 2004). Most of this was due to mothers reporting insufficient breast milk to satisfy their baby. Breastfeeding rates according to level of education was found higher among less educated mothers; the main reason for that was mothers returning to their jobs or study (Al-Bustan.1987, Khoja and Farid in 2000, Al-Jassir et al in 2004). Breastfeeding in public is accepted if the mother covers her breasts leading to positive attitudes towards mother's milk as the best nutritious food, or beliefs that breastfeeding is a mother's duty dictated by Islamic religion. Overall, Breastfeeding in KSA is the norm with family and peers are able to assist with understanding of why mothers choose to breastfeed. 


\section{A social-constructionist view: why do levels differ between the two regions?}

Levels of breastfeeding initiation are much higher in the Middle East compared to Western cultures. Here are six main comparative factors that will be critically analyzed in relation to breastfeeding durations between the two cultures to explore why these differences might occur. Can breastfeeding duration be attributed to social, cultural and psychological differences between the two cultures?

\section{Firstly: Mothers attitudes towards breastfeeding}

Mothers attitudes is an essential factor that contributes to the level of breastfeeding in KSA being higher than the UK. It could be seen that the attitudes of women in the UK are negative which are associated with formula use and believe that breastfeeding is inconvenient and ties them to the baby (Earle, 2000) or believe that formula milk will make the baby settled and sleep longer (Thulier\& Mercer, 2009).Also, returning to work is associated with using formula milk (Hoddinott, Tappin, \& Wright 2008; Ogbuanuet al. 2011a). Moreover, Mothers in the UK want to be able to share feeds with others, to be able to leave the baby and to 'get their lives back’ (Murphy, 1999).

On the other hand, the attitudes of Saudi mothers are positive. 98\% of mothers agree that mother's milk is the most nutritious baby food (Al-Bustan, 1987). The only problem was found in the KSA is starting bottle-feeding early beside breastfeeding. Namely, exclusive breastfeeding up to six months in the KSA is very far from compliance with WHO recommendation (El Mouzan et al 2009). This is due to mothers returning work or education (Al-Jassiret al 2006).

Therefore attitudes towards breastfeeding differ between the two cultures. Whilst women in Saudi Arabia view breastfeeding as positive and the best nutrition for their infant, mothers in the UK are more likely to see negative aspects such as the 
inconvenience and difficulty. Women in Saudi Arabia are thus more likely to view breastfeeding as something positive to do.

\section{Secondly: Attitudes of others towards breastfeeding}

Breastfeeding in both UK and KSA is influenced by attitudes of other people. In the UK, the attitudes of fathers have strong effects (Murphy, 1999), however many mothers report that their partner is negative towards breastfeeding feeling like he cannot share in infant care or feeling jealous of the baby (Thulier\& Mercer, 2009). Also, women in the UK often receive negative comments from family and friends which are associated with opting for bottle-feeding (Ingram et al, 2002).

In KSA however, attitudes towards breastfeeding from family and peers are often supportive with greater understanding and support for why the mother is choosing to breastfeed (Ogbeideet al , 2004). Therefore, in KSA there is a general acceptance that breastfeeding is the norm meaning that women are more likely to choose breastfeeding.

Attitudes and support from family and peers are therefore critically different between the two cultures, affecting how many women choose to initiate and continue breastfeeding.

\section{Thirdly: Attitudes towards breastfeeding in public}

One of the key factors mothers state for not breastfeeding in the UK is that they feel embarrassed or ashamed to do so in public. Attitudes can be critical and negative towards women who choose to breastfeed in front of others with the suggestion it should be done in private. This then puts women off breastfeeding (Dykes et al, 2003). Women are also embarrassed by factors such as leaking nipples, changes in the appearance of the breast and feeling that the infant still owns her body (Arora et al, 2000). All these reasons contribute to the use of 
formula feed to avoid embarrassment. Moreover, the sexual nature of breasts ultimately links breastfeeding with female sexuality (Squire, 2009). All these factors lead to bottle feeding.

However in the KSA and the Middle East in general, women can breastfeed in restaurants, parks and shopping malls without facing difficulties or problems. The one thing they need is to use cover up to help them not to expose their breasts while breastfeeding (Philips, 2004).

As a result, Breastfeeding in public differs between the two cultures. Whereas women in Saudi Arabia do not face difficulties and feel confident to do so, mothers in the UK are more likely to feel embarrassed and less confident.

\section{Fourthly: Maternal knowledge and confidence}

Increased maternal knowledge of breastfeeding enhances confidence and therefore duration. Problems associated with breastfeeding often lead to formula feeding. Problems such as getting the infant to latch on correctly, pain from sore or cracked nipples or infections such as mastitis and thrush can all lead to formula use (Scott, Binns, Oddy\& Graham, 2006; Wambach, Campbell, Hill, Dodgson, Abiona\&Heinig, 2005).

Women in the UK often do not know how to overcome these problems or think they are a reason to stop breastfeeding (Thulier\& Mercer, 2009). Mothers can find these difficulties very distressing, both emotionally and physically(Amir \& Ingram, 2008). Also, women in the UK might not have confidence that they produce quantity and quality of milk sufficient to their infants' growth and development ( $\mathrm{Li}$, Fein, Chen \&Grummer-Strawn, 2008). These misconceptions are often passed down by older generations and peers. In particular, grandmothers can pass on out of date knowledge with women feeling pressure to follow what their elders and peers 
suggest (Sachs, Dykes \& Carter, 2006).Again this leads to women choosing for formula feed.

Conversely, Grandmothers in The Middle East such as KSA and Kuwait have always been valuable antenatal support providers (Al-Bustan,1987). Support from Health Professionals is also rated highly (Al-Jasser et al 2006). Thus women in KSA have greater knowledge and guidance to breastfeed, enhancing rates.

Therefore, increased maternal knowledge of breastfeeding enhances confidence and duration towards breastfeeding. This is a difference between the two cultures; as women in Middle East are more confident with supporting grandmothers and medical staff, mothers in the UK are less likely to be confident with Some of the misconceptions are often passed down by older generationsalthough awareness of breastfeeding benefits has been rapidly increasing in the UK(Sachs, Dykes \& Carter, 2006).

\section{Fifthly: Support systems for breastfeeding}

Another reason for the difference in rates of breastfeeding is support systems, although the UK is thought to have better education on breastfeeding and has a system in place for mothers to be taught to breastfeed, with the aid of midwives visiting their homes during the early stages. Having a large support network once the mother arrives home has the largest influence on the duration of breastfeeding (Ogbuanu et al. 2011a). A number of studies have shown that mothers are affected by not having enough professional support to breastfeed. Mothers are more likely to initiate and continue breastfeeding when professional guidance and support is strong. Many mothers find that health professionals are too busy to give support and often offer formula milk as a solution (Brown \& Lee, 2011).

In the KSA and Middle East generally, grandmothers' support is one of the main reasons for the high rate of breastfeeding(Al-Bustan 1987). However, in recent 
years, and since Baby Friendly Hospital Initiative Program has been implemented in the kingdom, other support systems started to take place. For example; support from health professionals and medical staff was found high (Al-Jasser et al 2006). After delivery, midwives do not visit mothers after leaving hospitals; therefore, a mother with her infant can stay up to 40 days over her parents' place, where she gets all the support and advice required to help her care for her newborn. Mothers are also less likely to go back to work soon after having a baby than in the UK and are supported by their families in this (Ogbuanu et al. 2011b).

Overall professional and familial support for breastfeeding is much greater in KSA than the UK leading to more women continuing breastfeeding.

\section{Sixthly: Religious views}

Levels of breastfeeding are much higher in the Middle Eastern compared to Western cultures. Perhaps the reason for that is breastfeeding is socially constructed in the east more than it is in the west. The Middle East is an Islamic domain, and breastfeeding was dictated by Islamic rules set up in the holly book Al Quran. Therefore, Islamic societies do not necessarily need scientific approval of breastfeeding benefits. Muslim mothers breastfeed because it is deeply rooted in their religious beliefs. "Breastfeeding is not a new outlook within the Middle East; it was raised from Islamic culture since 1400 years. Unlike the Western Culture where it was firstly believed that cow's milk was more beneficial for an infant"(Al Habal, 2008).

Christianity is the main religion in the UK, $72 \%$ of the population are Christian (Census; Office for National Statistics, 2001). Breastfeeding has a great value in Christian religion. Many examples in the Holly Bible show the religious 
perspective of the importance of breastfeeding to both mother and baby. However, religion in the UK has a low impact upon maternal decision to breastfeed. Overall, comparing the two cultures, the KSA has much more positive social and cultural views towards breastfeeding. Breastfeeding is more acceptable, there is more expectation that women will breastfeed and knowledge and experience are stronger meaning that women are supported and guided in their decision to breastfeed. Breastfeeding is more acceptable in public and viewed as normal rather than embarrassing meaning that women are encouraged to breastfeed. Overall breastfeeding in KSA is constructed as something normal within the culture whereas in the UK formula feeding has become the norm.

\section{Conclusion}

We have concluded that breast is best with major influential organizations that all agree mothers should exclusively breastfeed their infant up to six months of age as breast milk is an optimal form to meet infants' nutritional needs. Organizations include, The World Health Organization (WHO), The United Nations Children's Fund (UNICEF), The American Academy of Pediatrics (AAP), The UK Department of Health (UK DoH) and Health Ministries in the Middle East.

This paper particularly focused on two areas of breastfeeding; a comparison between KSA and UK in breastfeeding and how breastfeeding is socially constructed in two contradictory cultures.

Despite this, levels of breastfeeding vary across the World. Particularly in Western societies, breastfeeding initiation and duration is low with few women exclusively breastfeeding. This is in contrast to other societies, mainly Middle Eastern areas where rates of breastfeeding are much higher. For example, in 2005, 76\% of mothers in the UK initiated breastfeeding at birth compared to $91.6 \%$ of mothers in the Kingdom of Saudi Arabia. Breastfeeding rates have increased since this time 
but still there remains a gap between the East and the West. The percentage rates in the USA reached to $73.9 \%$ in 2007-08 whereas the state of Kuwait reached to 92.5 $\%$ in 2010. The main aim of this work was to consider why rates of breastfeeding differed between the two cultures. Was there some biological difference between the two regions or could the difference be explained by social, cultural and psychological differences that affected initiation and duration rates?

Breastfeeding is a complex phenomenon associated with many multiple variables including demographic, biological, social, religious and psychological variables (Thulier\& Mercer, 2009). A woman's decision to breastfeed is highly affected by the level of support she faces alongside her attitudes and those of the people supporting her. Women who are well supported, encouraged and guided to breastfeed are more likely to do so than those who are not. Through extensive research it is clear that breastfeeding in the KSA is greatly supported by family members and society in general. Newly mothers have the opportunity to stay at their parents' house for up to 40 days. Here grandmothers and other influential family members support mothers and pass down positive attitudes towards breastfeeding. In the UK family members that influence newly mothers generally tend to be the father of the child, if the father does not support breastfeeding and wants to participate in the feeds then women choose bottle feeding. In general society is not accepting of breastfeeding feeling it is embarrassing, inconvenient and should be kept private. Support and guidance is poor. All in all these factors lead to low breastfeeding rates in the UK.

In conclusion this study has shown that breastfeeding rates in the Kingdom of Saudi Arabia are much higher than rates in the United Kingdom and at least in part can be explained by complex social, cultural and psychological differences. Overall 
breastfeeding is perceived as the cultural norm in KSA with women encouraged and supported to do so whilst in the UK formula feeding is the norm and encouraged. If breastfeeding was perceived in the same way as it is in KSA in the UK many more women might initiate and continue breastfeeding.

\section{Reference List:}

Al-Ayed IH \& Qureshi MI.(1998). 'Breastfeeding practices in urban Riyadh'. J Trop Podiatry, Vol.44,pp.113-117.

Al-Bustan MH.(1986). 'Attitudes and practice of Kuwaiti women toward breastfeeding', International Quarterly of Community Health Education, Vol.1:7, No.2,pp.135-48.

Al-Fadli, H., Al-Jasem, L. \&Masoud.G. (2004). 'Factors Influencing the Mother's Decision to Breast-Feed in Ahmadi Region, Kuwait' ,Kuwait Medical Journal, Vol. 36 , No2, pp. 108-112.

Al Habal, M. (2008).Breastfeeding under Islam law, [Online] Available at: http://www.menokia.com/vb/showthread.php?t=58137\&page=1 \& $\underline{\text { http://www.palm }}$ oon.net/2/topic-2803-190.html [Accessed: 22/05/2011].

Ali ibinabetalib, nahaij al bala3'a; explained by Imam Mohamed Abdou (1990). Al-Ma'arf Institution, Beirut, Lebanon.

Al-Jassir,M. El-Bashir,M. \&Moizuddin,S. (2004).'Surveillance of infant feeding practices in Riyadh city'. Annals of Saudi medicine, Vol.24, No.2, pp.136-40.

Al-Jassir, M., El-Bashir, B. \&Moizuddin, S., and Abu-Nayan, A. (2006).'Infant feeding in Saudi

AL Jazairi, H. (2011) ,Advice on feeding infants and young children, Regional Office of WHO in Middle East. 
Al Rifaae, M. (2006).What are the elements of the Islamic Education?, [Online] Available at: http://www.kenanaonline.com/blog/46762/page/947 [Accessed: 25/05/2011].

Al Shamasy, A. ,Ruwaili, M., Al-Ahmad, B., Al Dosari,A., AL geshawi, M., AlAmari, S., Almusharf, Kh., Azzaz,M. \&Albather,J.(1999).Baby-friendly hospital; Program to encourage breastfeeding, Maternity and children hospital , Dammam, Saudi Arabia.

Al-Shehri, S., Farag, M.,Baldo, M., Al-Mazrou, Y .\&Aziz , K. (1995). 'Overview on Breastfeeding Patterns in Saudi Arabia', Journal of Tropical Pediatric, Vol. 41 No.1, pp.38-44.

American Academy of Pediatrics (2005). 'Policy Statement; Breastfeeding and the Use of Human Milk',Journal of the American Academy of Paediatrics, Vol. 115, No. 2, pp.460-506.

American Academy of Pediatrics, "AAP Policy on Breastfeeding", [Online] Available at http://www.aap.org/breastfeeding/PolicyOnBreastfeeding.html [Accessed: 20/07/2011]. Amile, A.(1971). Al wasaal; part XV, Dar Ahia'aTurath AL Arabi, Beirut, Lebanon [Online] Available at: http://www.alseraj.net/a-k/hadith/ws/ws.htm [Accessed: 24/05/2011].

Amin, T., Hablas, H. \& Al-Abd Al Qader A. (2011).'Determinants of Initiation and Exclusivity of Breastfeeding in Al Hassa, Saudi Arabia', King Faisal Specialist Hospital and Research Centre, Riyadh, Saudi Arabia, Vol. 6, No 2.

Amin, R., Said, Z., Sutan, R., Shah, S., Darus, A. \&Shamsuddin, K.(2011). 'Work related determinants of breastfeeding discontinuation among employed mothers in Malaysia', International Breastfeeding Journal, vol. 6, no.4, pp.1-6. 
Amir \& L., Ingram, J. (2008). 'Health Professionals Advice for Breastfeeding Problems Not Good Enough!',International Breastfeeding Journal, Vol. 3.No.22, pp.1-2.

Annan, K. (2000).United Nations Information Services, Bangkok, [Online] Available athttp://www.unescap.org/unis/press/G_05_00.htm [Accessed: $15 / 07 / 2011]$.

Arora, S., Mc Junkin, C., Wehrer, J. \& Khun, P. (2000). 'Major Factors Influencing Breastfeeding Rates: Mothers Perception of Fathers Attitude and Milk Supply', Pediatrics, Vol. 106, No.5, pp.1-5.

Baxter, J., \&Cooklin, A.R. (2009). Which mothers wean their babies prematurely from full breastfeeding? An Australian cohort study.ActaPaediatrica, 98, 1274 1277.

BBC (2009).Religions; The Quran [Online] Available at http://www.bbc.co.uk/religion/religions/islam/texts/quran_1.shtml[Accessed: 2/06/2011].

Berridge, K., McFadden, K., Abaymoi, J. \& Topping, D.(2005). Views of breast feeding difficulties among drop in clinic attendees.Maternal and Child Nutrition, 1, $250-62$.

Blyth, R., Creedy, D. K., Dennis, C. L., Moyle, W., Pratt, J., \& De Vries, S. M. (2002). 'Effect of Maternal Confidence on Breastfeeding Duration: An Application of Breastfeeding Self-Efficacy Theory', Birth, vol. 29, no. 4, pp. 278-284.

Bolling K, Grant C, Hamlyn B, Thornton A. (2007).Infant Feeding Survey 2005. The Information Centre: London. 
Boselery, S. (2011).Breastfeeding by UK mothers rises from $76 \%$ to 81\%,guardian.co.uk, Tuesday 21 June 2011, [Online] Available at http://www.guardian.co.uk/lifeandstyle/2011/jun/21/breastfeeding-rate-rise-ukmothers [Accessed: 23/08/2011].

Brown, A \& Lee, M. (2011).'An Exploration of the Attitudes and Experiences of Mothers in the United Kingdom Who Chose to Breastfeed Exclusively for 6 Months Postpartum', Breastfeeding Medicine, vol. 6, no. 4, pp. 197-204.

Brown, A. ,Raynor, P. \& Lee, M. (2009). 'Young mothers who choose to breastfeed: the importance of being part of a supportive breastfeeding community'. Midwifery ,doi:10.1016/j.midw.2009.09.004.

Census, Office for National Statistics (2001).Religious Populations, [Online] Available at http://www.statistics.gov.uk/cci/nugget.asp?id=954[Accessed: 8/07/2011].

Chezem, J., Friesen, C. \& Boettcher, J. (2003). Breastfeeding knowledge, breastfeeding confidence and infant feeding plans: effects on actual feeding practices. J Obstet Gynecol Neonatal Nurs, 32, 40 - 7.

Cleveland, A. \& McCrone, S. (2005). 'Development of the Breastfeeding Personal Efficacy Beliefs Inventory: A Measure of Women's Confidence About Breastfeeding', Journal of Nursing Measurement, Vol. 13, No. 2, pp. 115-127.

Dashti, M., Scott, J., Edwards, C., Al-Sughayer, M., (2010).'Determinants of breastfeeding initiation among mothers in Kuwait', International Breastfeeding Journal, vol. 5, no.7, pp.1-9. 
Department of Health.(2007). Birth to five.COI: London UK.

Dewey KG. (2001). 'Nutrition, growth and complementary feeding of the breastfed infant', Pediatric Clinics of North America, Vol. 48, No.1, pp, 87-104.

DiGirolamo, A.M., Thompson, N., Martorell, R., Fein, S.B., \&Grummer-Strawn, L.M. (2005).'Intention or experience?Predictors of continued breastfeeding'.Health Education and Behaviour, 32/2, $208-226$.

Dogramaky, I. (2005). Breastfeeding in Islam, [Online] Available at: http://www.ala7ebah.com/upload/showthread.php?t=12892 [Accessed: 22/05/2011].

Dykes, F., Moran, V.H., Burt, S., \& Edwards, J. (2003).'Adolescent mothers and breastfeeding. Experiences and support needs - An exploratory study'. Journal of Human Lactation, 19, $391-401$.

Earle, S. (2000), 'why some women do not breastfeed: bottle feeding and fathers role', Midwifery, Vol. 16, No.4, pp 323-30.

El Mouzn, M, Al Omar, A., Al Salloum, A., Al Herbish, A., Qurach, M. (2009), 'Trend in infant nutrition in Saudi Arabia: compliance with WHO recommendation',

Annals of Saudi Medicine, Vol. 29, No.1, pp.20-23.

Entwistle, F., Kendall, S., Mead, M. (2007), 'The promotion of breastfeeding among low-income women: midwives' knowledge attitudes following a 
WHO/UNICEF breastfeeding management course', Midwifery, Vol.5, No.1, pp2934.

Hoover, K. (2002). Delayed lactogenesis II secondary to gestational ovarian theca lutein cysts in two normal singleton pregnancies.Journal of Human Lactation, 18/3, $264-268$.

Huggins, K. (2000). 'Markers of lactation insufficiency: a study of 34 mothers'. Current issues in Clinical Lactation, 1, 25 - 35.

Ingram, J., Johnson, D., \& Greenwood, R. (2002). Breast Feeding in Bristol: Teaching good positioning, and support from fathers and families. Midwifery, 18, $87-101$.

Khalil K. Al-Ghamdi Y, Al-Yahia O Subahee A \&Sate B. (2003). 'Pattern of breastfeeding of preterm infants in hospitals and after discharge'.Ann Saud Med, Vol. 23, pp.220-222.

Khoja T. \&Farid S., (2000). 'Gulf Family Health Survey, Kingdom of Saudi Arabia', Published by Council of Health Ministers of GCC States, King Fahad National Library Riyadh, Saudi Arabia.

Kent, G. (2006). 'WIC's promotion of infant formula in the United States', International Breastfeeding Journal, vol. 1, no. 8, pp. 1-14. 
Kramer, M.S. \& Kakuma, R. (2002). 'Optimal Duration of Exclusive Breastfeeding'. Cochrane Collaboration [Online] Available at: http://www2.cochrane.org/reviews/en/ab003517.html [accessed: 11.07.11].

Lee, E. (2011). 'Feeding babies and the problems of policy', Center for Parenting Culture Studies (CPCS), University of Kent.

Lewallen, L., Dick, M., Flowers, J., Powell, W., Zickefoose, K., Wall, Y. \& Price, Z. (2006).Breastfeeding support and early cessation.The Association of Women's health, obstetric and neonatal nurses, March/April 2006.

Li. R., Fein, S., Chen, J. \&Grummer, L., (2008).'Why Mothers stop Breastfeeding: Mothers' Self-reported Reasons for Stopping During the First Year',Pediatrics, 122;S69.

Maternity action (2011).breastfeeding in public, Maternity action information sheet breastfeeding in public place. [Online] Available at http://www.maternityaction.org.uk/sitebuildercontent/sitebuilderfiles/breastfeeding publicplace.pdf [Accessed: 6/09/2011].

McFadden, A. \& Toole, G. (2006).Exploring womens views of breast feeding: a focus group study within an area with high levels of socio - economic deprivation.Maternal and Child Nutrition, 2, $156-168$.

Miracle, D., Meier, P., \& Bennett, P. (2004). Mothers decision to change from formula to mothers milk for very-low-birth-weight infants. J ObstetGynecol Neonatal Nurs, $692-703$.

Mohrbacher, N. \& Stock, J. (2003).The breastfeeding answer book. La Leche League International: Illonois. 
Muers, R. (2010). 'The Ethics of Breast-Feeding A Feminist Theological Exploration',

Journal of Feminist Studies in Religion, Vol. 26, No.1, pp. 7-24.

Murkoff, H., Eisenberg, A. \& Hathaway, S. (2009). What to Expect the first years?

Arabic version translated, Jarir Bookstore, Riyadh, Saudi Arabia.

Murphy, M. (1999). 'Breast is best': infant feeding decisions and maternal deviances, Sociology of Health and Illness, Vol.21, No.2, pp187-211.

Neifert, M.R. (2001). 'Prevalence of breastfeeding tragedies'.Pediatrics Clinics of North America, 48 (2), 273 - 297.

Ogbeide DO, Siddiqui S, Al Khalifa IM \&Karim A. (2004).' Breast feeding in a Saudi Arabian community.Profile of parents and influencing factors'.Saudi Med J, Vol.25, pp.580-584. 
Ogbuanu, C., Glover, S., Probst, J., Liu, J., \& Hussey, J. (2011a). 'The Effect of Maternity Leave Length and Time of Return to Work on Breastfeeding', Pediatrics, vol. 127, no. 6, p. e1414-e1427.

Ogbuanu, C., Glover, S., Probst, J., Hussey, J., \& Liu, J. (2011b). 'Balancing Work and Family', Journal of Human Lactation, vol. 27, no. 3, pp. 225-238.

Philips (2004).The most important tips for breastfeeding in public places(20042011) Koninklijke Philips Electronics N.V,[Online] Available at http://www.philips.com.sa/c/public-breastfeeding-tips/179429/cat /[Accessed: 27/06/2011].

Powers, N. (1999). Slow weight gain and low milk supply in the breastfeeding dyad. Clinical Perinatology, 26/2, 399 - 430.

Riordan, Jan. (2005).'Breastfeeding and Human Lactation'. Sudbury, MA: Jones and Bartlett.

Saadeh, R. \&Akre, J. 1(996). 'Ten Steps to Successful Breastfeeding: A Summary of the Rationale and Scientific Evidence', Birth, vol. 23, no. 3, pp. 154-160.

Sachs, M., Dykes, F., \& Carter, B. (2006). Feeding by numbers: an ethnographic study of how breastfeeding women understand their babies' weight charts.International Breastfeeding Journal, 1, 29.

Scott, J.A., Binns, C.W., Oddy, W.H., \& Graham, K.I. (2006). Predictors of breastfeeding duration: Evidence from a cohort study. Pediatrics, 117, 646 - 655 .

Scott, J.A., Mostyn, T. \& Greater Glasgow Breastfeeding Initiative Management Team.(2003). Women's experiences of breastfeeding in a formula feeding culture'.Journal of Human Lactation, Vol.19, pp. 270 - 7.

Squire, C. (2009).The social Context of Birth,Radeliffe publishing Ltd.UK.

The Holy Bible (English copy) http://bible.org/netbible/index.htm[Accessed: 24/05/2011]. 
The Holy Quran (English copy) https://quran.com/?local=en https://quran.com/?local=en [Accessed: 24/05/2011].

The NHS information Center \& IFF research (2011). Infant Feeding Survey 2010: Early Results, NSH: The Information Center for Health and social Care Thulier, D. \& Mercer, J. (2009). 'Variables associated with breastfeeding duration', JOGNN, 38, $259-268$.

Trading Economics, (2011).Exclusive breastfeeding (\% of children under 6 months) in Saudi Arabia, [Online] Available athttp://www.tradingeconomics.com/saudi-arabia/exclusive-breastfeeding-percentof-children-under-6-months-wb-data.html[Accessed: 25/05/2011].

Wambach,K., Campbell, S. H., Gill, S. L., Dodgson, J. E., Abiona, T. C., \&Heinig, M. J. (2005). 'Clinical lactation practice: 20 years of evidence', Journal of Human lactation, Vol. 21,pp245-258.

Wambach, K., \& Cohen, S.M. (2009). Breastfeeding experiences of urban adolescent mothers. Journal of pediatric nursing, 24/4, $244-254$.

Wiessinger, D. (1996). 'The Language of Breastfeeding', Journal of human lactation', vol. 12, No. 1, [Online] Available at http://www.bobrow.net/kimberly/birth/BFLanguage.html[Accessed: 6/06/2011].

World Health Organization (1991).World Health Organization: Indicators for Assessing Breastfeeding Practices: Geneva Switzerland, Division of Child Health and Development.

World Health Organization, Infant and young child feeding data by country.[Online] Available at http://www.who.int/nutrition/databases/infantfeeding/countries/en/index.html [Accessed: 30/05/2011]. 
World Health Organization (2003).Complementary feeding. Report of the global consultation, and summary of guiding principles for complementary feeding of the breastfed child.

World Health Organization (2003).Global databank on breastfeeding.[Online] Available at https://apps.who.int/nut/db_bfd.htm[Accessed: 23/09/2011].

World Health Organization (2009).10 facts on breastfeeding, WHO [Online] Available at http://www.who.int/features/factfiles/breastfeeding/en/index.html[Accessed: 27/06/2011].

World Health Organization (2006-2011).Country Cooperation Strategy for WHO and Saudi Arabia, [Online] Available at http://www.who.int/countryfocus/cooperation_strategy/ccs_sau_en.pdf]Accessed: 6/06/2011].

World Health organization (2011).Up to what age can a baby stay well nourished by just being breastfed, WHO, [Online] Available at http://www.who.int/features/qa/21/en/index.html[Accessed: 27/06/2011]. Zimmerman, D., Guttman, N. (2001). 'Breast is Beast: Knowledge among LowIncome Mother is not Enough',Journal of Human Lactation ,Vol.17, No.1, pp. 14 19. 